Article

\title{
Building Damage Assessment Using Scenario Based Tsunami Numerical Analysis and Fragility Curves
}

\author{
Khawar Rehman and Yong-Sik Cho * \\ Department of Civil and Environmental Engineering, Hanyang University, 222 Wangsimni-ro, \\ Seongdong-gu, Seoul 04763, Korea; khawarrehman@hanyang.ac.kr \\ * Correspondence: ysc59@hanyang.ac.kr; Tel.: +82-2-2220-0393 \\ Academic Editor: Yunqing Xuan \\ Received: 19 December 2015; Accepted: 16 March 2016; Published: 19 March 2016
}

\begin{abstract}
A combination of a deterministic approach and fragility analysis is applied to assess tsunami damage caused to buildings. The area selected to validate the model is Imwon Port in Korea. The deterministic approach includes numerical modeling of tsunami propagation in the East Sea following an earthquake on the western coast of Japan. The model is based on the linear shallow-water equations (LSWE) augmented with Boussinesq approximation to account for dispersion effects in wave propagation, and coastal wave run-up is modeled by non-linear shallow-water equations (NLSWE). The output from the deterministic model comprises inundation depth. The numerical output is used to perform fragility analysis for buildings vulnerable to flooding by tsunamis in the port area. Recently developed fragility curves-based on the ordinal regression method-are used for damage probability estimates. The extent of structural damage in the areas under a tsunami hazard is identified by the numerical modeling of tsunami features. Our numerical model offers high bathymetric resolution, which enables us to capture flow features at the individual structure level and results in improved estimation of damage probability. This approach can serve as a measure of assessing structure vulnerability for areas with little or no records of tsunami damage and provide planners with a better understanding of structure behavior when a tsunami strikes.
\end{abstract}

Keywords: fragility analysis; tsunami modeling; tsunami hazard; floods; inundation depths; structures

\section{Introduction}

Climate change and its increasing unpredictability, along with an increase in the population, have resulted in increased vulnerability of communities to disasters. Frequent occurrences of floods caused by storms, torrential rains, and tsunamis have affected large swaths of the population all over the world in the past few decades. In the past two decades, 58 tsunamis with a maximum run-up height greater than $3 \mathrm{~m}$ were recorded around the world [1]. Areas hit by recent mega tsunamis experienced adverse effects in social structure and economic growth. The 2004 Indian Ocean Tsunami caused devastation in 11 countries, and the monetary damage was approximated around 10 billion US dollars with extensive infrastructure damage [2]. The 2010 Chilean tsunami and earthquake resulted in a few hundred causalities; 81,000 structures were destroyed and around 109,000 were severely damaged [3]. The 2011 Great East Japan tsunami caused property damage of around 300 billion US dollars, with more than 400,000 buildings reported to be damaged or destroyed [4]. Robust disaster mitigation techniques are necessary for avoiding property damage and human losses.

In this paper, we study tsunami hazard assessment for buildings. Fragility curves are a preferred method to produce vulnerability information regarding structures affected by a number of features [5]. The concept of tsunami fragility was introduced in [6] to assess tsunami damage using remote sensing, numerical model results, field surveys and historical records to develop estimates of structure fragility and fatalities. Following the 2004 and 2011 tsunamis, the concept of fragility curves for structures 
gained popularity, because it offers a comparatively more economical and faster way to assess structural vulnerability. Most of the studies on fragility curves have focused on the damage caused to structures by inundation depths $[4,7,8]$. Fragility curves for structures can be based on various methods including professional judgement, design codes, information from past events, and numerical simulation [5].

Common flooding hazard assessment techniques include direct field-based measurements, field data interpolation, and inundation modeling [1]. Tsunami flow characteristics for fragility curves can be approximated by field inspection, numerical modeling, or a combination of both methods. We assess the hazard posed by tsunamis to coastal areas with deterministic and parametric approaches.

Since the introduction of tsunami fragility curves, numerical models have been used extensively [9-13] in combination with statistical approaches and field inspections to compensate for any missing information on flow features and for comparison. It was recommended in [1] to use high resolution hydrodynamic inundation modeling techniques for better estimation of flow conditions at the individual building level and to capture the features of bathymetry in detail. To our knowledge, among the numerical models (including commercial programs) used for tsunami fragility studies, the finest grid resolution for the computational domain modeled to date is $20 \mathrm{~m}$, reported in [14]; this resolution is not sufficient to accurately capture tsunami flow features for densely populated areas, where structures are confined. Therefore, we address this shortcoming of the existing models in our study by presenting a numerical model with a nested grid divided into six levels, with the finest resolution of $4.5 \mathrm{~m}$ adopted for the land area. Our numerical model considers the effects of local topography and coastal defense structures on the inundation depths. The location and building material of structures were assessed by field survey and by street view (Naver map, 2015).

The fragility functions are defined by applying regression analysis to observations classified into various damage states, based on hydrodynamic feature intensity; therefore, the choice of regression technique influences structure vulnerability evaluation. Various analysis methods are used; logistic regression [15], least square regression [4,9], and most commonly, the linear regression method [3,16,17]. Robust parametric approaches to assess flood hazard by tsunami are still a matter of debate, as there is no clear consensus regarding the best approach. Commonly used regression methods including linear and logistic regression have the disadvantages of presenting damage uncertainty and partial utilization of damage information, respectively [18]. Therefore, we performed fragility analysis for structure damage by choosing fragility curves proposed recently in [9]; they derived fragility curves using ordinal regression analysis based on the Generalized Linear Model (GLM), which addresses the issues associated with linear and logistic regression methods.

This study focuses on the property damage caused by tsunami inundation because our study area (Imwon Port, Korea) is not believed to be at direct risk of structural damage from ground motions caused by earthquakes in the East Sea. Most of the studies on the numerical tsunami propagation to the eastern coast of Korea [19-21], including the Imwon port [22-24], discuss flow features and their variation with changes in topography and safety practices (evacuation and provision of safety structures). However, considering the high population density and key housing/industrial facilities at Imwon port, there is a need to understand the building behavior in response to tsunami flooding to devise elaborate design practices for safety purposes.

Several damage classifications of buildings are in practice. There are two primary methods to determine damage classification: remote sensing by satellite and field surveys, which are often used in combination. Damages observed by remote survey are mostly classified into two major states, survived or collapsed, depending upon the state of the roof of the building. Post-tsunami field surveys usually classify damage states into 4 to 6 classes depending on the extent of the damage and parts of the building that are impaired. Four damage states (minor, moderate, major, and complete) were used in [12] to describe damage to windows through to columns. Suppasri et al. [25] also classified damage into four states, from minor to complete, for the 2011 Great East Japan tsunami. After the 2009 South Pacific tsunami, Reese et al. [15] surveyed 201 buildings and classified the damage into five states (light, minor, moderate, severe, and complete) considering non-structural damage through 
to complete structure collapse. More details about common damage classification practices and their corresponding degree of structure damage can be found in Table 3 of [1].

The development of fragility curves depends on the existence of building damage data from post-tsunami field surveys and remote surveying. Most of the existing studies focus on assessing the vulnerability of structures in areas for which data on damage from tsunamis is available (Indonesia, Sri Lanka, Japan, Chile, Thailand, US Samoa, etc.). There is a need to extend this method to areas that are at risk of potential structural damage by tsunamis. To our knowledge, only a few studies to date have addressed this issue. Valencia et al. [7] developed damage functions for the European-Mediterranean coasts, for which no post-tsunami observations exist, by analyzing the structures damaged in Banda Aceh (Indonesia) after the 2004 Indian Ocean tsunami. Wiebe and Cox [12] estimated building damage and economic loss for Seaside, Oregon caused by a hypothetical tsunami using the inundation based fragility curves of [4]. Park et al. [13] used fragility curves based on flow depth, velocity, and momentum flux for establishing probabilistic damage levels and assessing the sensitivity of damage in response to tsunami features in Seaside, Oregon. We present the building damage assessment for Imwon Port to expand and refine the existing research for areas with no post-tsunami damage records. Compared to the three studies mentioned above, we used robust and advanced numerical and statistical methods to gain a better understanding of building damage response to inundation.

\section{Methods}

\subsection{Tsunami History in Korea}

The occurrence of submarine earthquakes is frequent around the Korean Peninsula; however, the magnitude of earthquakes needed to generate tsunamis is usually very small. The frequency of earthquakes around the Korean Peninsula for the last 15 years is shown in Table 1.

Table 1. Earthquake frequency around the Korean Peninsula for the last 15 years.

\begin{tabular}{|c|c|c|c|c|c|c|c|c|c|c|c|c|c|c|c|}
\hline Year & 2001 & 2002 & 2003 & 2004 & 2005 & 2006 & 2007 & 2008 & 2009 & 2010 & 2011 & 2012 & 2013 & 2014 & 2015 \\
\hline Frequency & 16 & 21 & 21 & 24 & 24 & 28 & 16 & 25 & 30 & 18 & 38 & 30 & 72 & 27 & 24 \\
\hline
\end{tabular}

Recent tsunamis that caused damage on the Eastern coast of South Korea are the 1964 Niigata tsunami, 1983 Central East Sea tsunami, and 1993 Hokkaido tsunami. These three historic tsunamis originated on the West Coast of Japan, and their positions are shown in Figure 1.

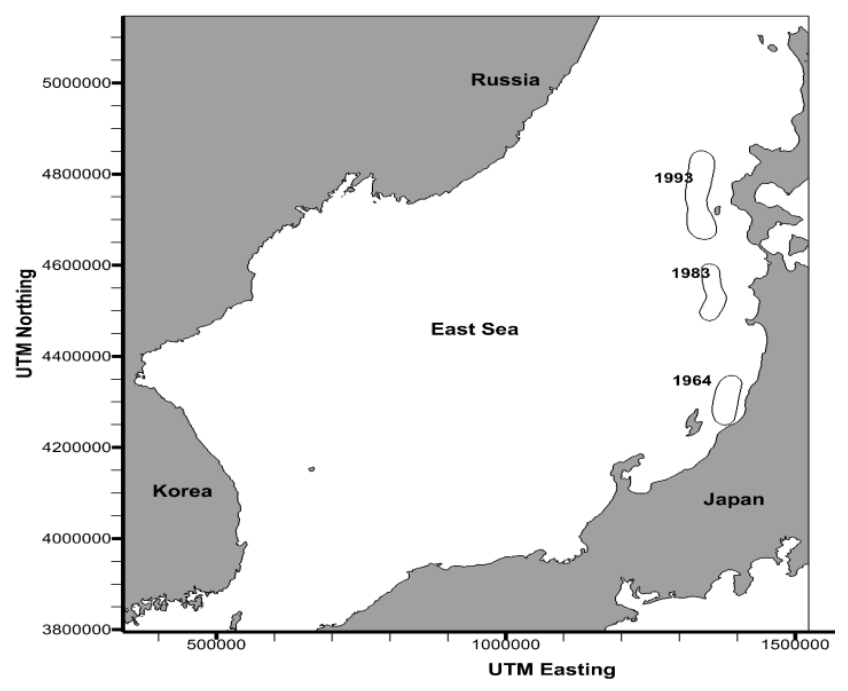

Figure 1. Locations of three historical tsunamis. 
The Korean Peninsula is at risk of 11 possible tsunamis due to highly probable earthquakes generated on the west coast of Japan; their locations were provided by the Korean Peninsula Energy Development Organization (KEDO) [26]. These 11 hypothetical tsunamis primarily differ in fault parameters and origin. Table 2 lists the location, magnitude, and other parameters of the hypothetical and historical earthquakes, and the locations of faults are shown in Figure 2. In Table 2, $H$ is the water depth, $\theta$ is the strike angle of the fault, $\delta$ is the dip angle, $\lambda$ is the slip angle, $L$ is the fault length, $W$ is the fault width, and $D$ is the fault dislocation. The length, width, and dislocation of faults are derived from equations proposed by the Korea Meteorological Administration (KMA).

$$
\begin{aligned}
& \log L=0.5 M-1.9 \\
& W=0.5 L \\
& \log D=0.5 M-1.2
\end{aligned}
$$

where $M$ is the earthquake magnitude, chosen as 8.0 for 11 hypothetical cases. The depth of the fault plane and dip and slip angle were obtained from [27]. We model these 11 hypothetical tsunamis along with 3 historic tsunamis $(1964,1983$, and 1993) to determine the maximum flooding in the Imwon Port area (shown in Figure 3) for each case.

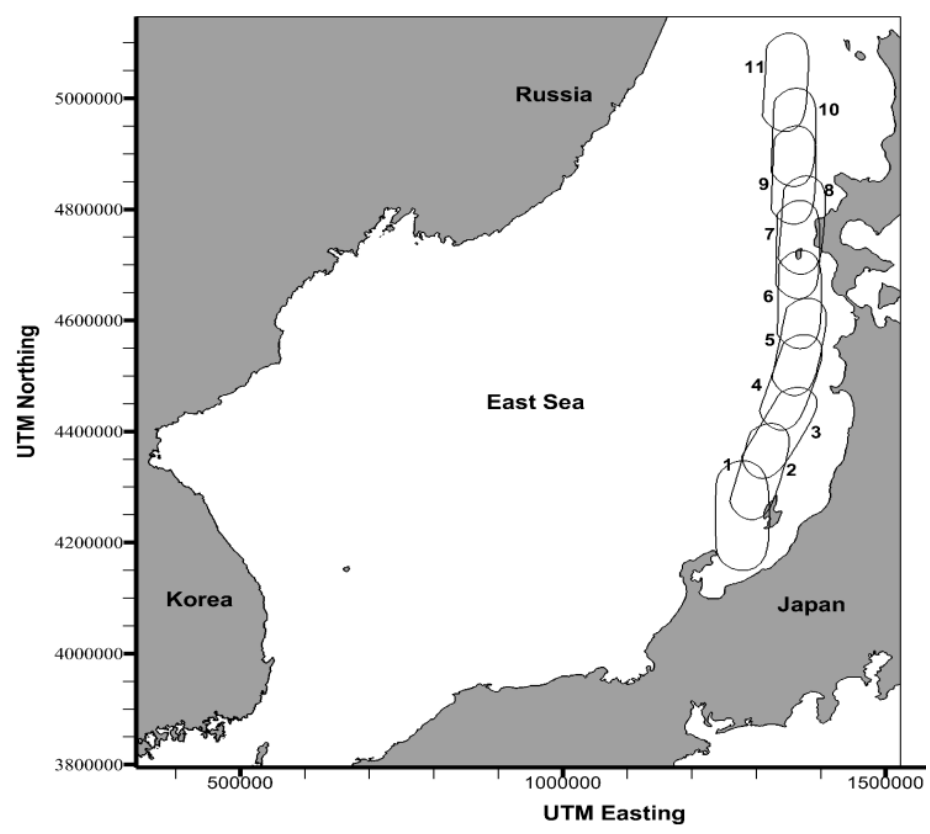

Figure 2. Locations of 11 hypothetical tsunamis.

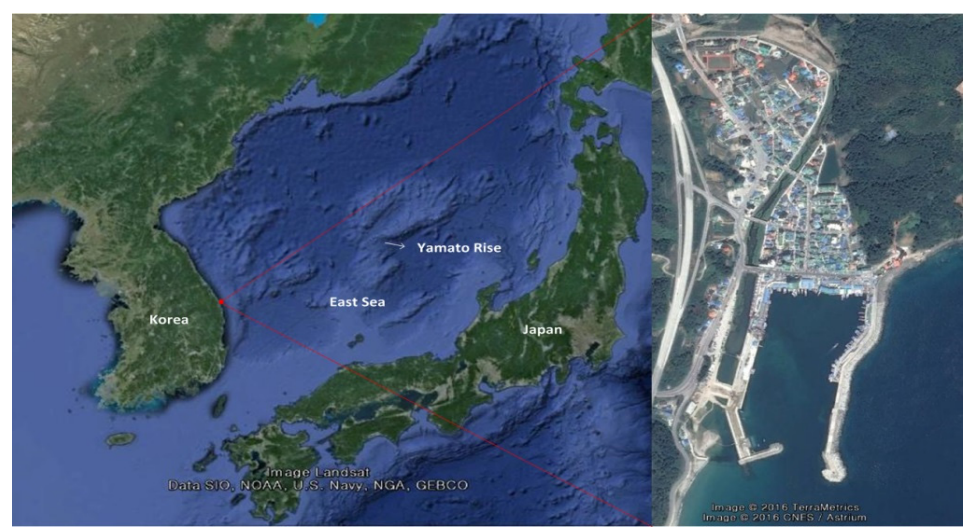

Figure 3. Location and map of Imwon Port. 
Table 2. Parameters for 11 hypothetical and 3 historical cases.

\begin{tabular}{|c|c|c|c|c|c|c|c|c|c|c|}
\hline \multirow{2}{*}{ Case } & \multicolumn{2}{|c|}{ Location } & \multirow{2}{*}{$H(\mathbf{k m})$} & \multirow{2}{*}{$\theta\left({ }^{\circ}\right)$} & \multirow{2}{*}{$\delta\left({ }^{\circ}\right)$} & \multirow{2}{*}{$\lambda\left({ }^{\circ}\right)$} & \multirow{2}{*}{$L(\mathrm{Km})$} & \multirow{2}{*}{$W(\mathrm{Km})$} & \multirow{2}{*}{$D(\mathrm{~m})$} & \multirow{2}{*}{ Magnitude } \\
\hline & Long. $\left({ }^{\circ} \mathrm{E}\right)$ & Lat. $\left({ }^{\circ} \mathrm{N}\right)$ & & & & & & & & \\
\hline 1 & 137.50 & 37.5 & 1.0 & 0.0 & 40.0 & 90 & 125.89 & 62.95 & 6.31 & 8.0 \\
\hline 2 & 137.70 & 38.3 & 1.0 & 14.5 & 40.0 & 90 & 125.89 & 62.95 & 6.31 & 8.0 \\
\hline 3 & 138.00 & 39.0 & 1.0 & 27.5 & 40.0 & 90 & 125.89 & 62.95 & 6.31 & 8.0 \\
\hline 4 & 138.40 & 39.7 & 1.0 & 17.0 & 40.0 & 90 & 125.89 & 62.95 & 6.31 & 8.0 \\
\hline 5 & 138.70 & 40.2 & 1.0 & 10.0 & 40.0 & 90 & 125.89 & 62.95 & 6.31 & 8.0 \\
\hline 6 & 138.90 & 40.9 & 1.0 & 1.0 & 40.0 & 90 & 125.89 & 62.95 & 6.31 & 8.0 \\
\hline 7 & 139.00 & 41.7 & 1.0 & 1.0 & 40.0 & 90 & 125.89 & 62.95 & 6.31 & 8.0 \\
\hline 8 & 139.10 & 42.1 & 1.0 & 4.0 & 40.0 & 90 & 125.89 & 62.95 & 6.31 & 8.0 \\
\hline 9 & 139.10 & 42.9 & 1.0 & 2.0 & 40.0 & 90 & 125.89 & 62.95 & 6.31 & 8.0 \\
\hline 10 & 139.20 & 43.5 & 1.0 & 2.0 & 40.0 & 90 & 125.89 & 62.95 & 6.31 & 8.0 \\
\hline 11 & 139.20 & 44.4 & 1.0 & 3.0 & 40.0 & 90 & 125.89 & 62.95 & 6.31 & 8.0 \\
\hline \multirow[t]{2}{*}{1964} & 139.42 & 38.74 & 1.0 & 189.0 & 56.00 & 90 & 80.00 & 30.00 & 3.30 & 7.5 \\
\hline & 139.02 & 40.54 & 3.0 & 355.0 & 25.00 & 80 & 60.00 & 30.00 & 3.05 & \\
\hline \multirow[t]{2}{*}{1983} & 138.84 & 40.21 & 2.0 & 22.0 & 40.00 & 90 & 40.00 & 30.00 & 7.60 & 7.7 \\
\hline & 139.30 & 42.10 & 5.0 & 163.0 & 60.00 & 105 & 24.50 & 25.00 & 12.0 & \\
\hline \multirow[t]{2}{*}{1993} & 139.25 & 42.34 & 5.0 & 175.0 & 60.00 & 105 & 30.00 & 25.00 & 2.50 & 7.8 \\
\hline & 139.40 & 43.13 & 10.0 & 188.0 & 35.00 & 80 & 90.00 & 25.00 & 5.71 & \\
\hline
\end{tabular}

\subsection{Study Area}

Imwon Port is located in the center of the eastern coast of South Korea. Yamato Rise, located in the East Sea (shown in Figure 3), refracts the tsunami waves propagating from the west coast of Japan at Imwon Port, causing the wave energy to be concentrated and consequently produce waves with higher run-up heights. Due to this effect, the run-up height observed at Imwon Port during the 1983 tsunami was approximately $4.0 \mathrm{~m}$ [28], causing severe damage. Imwon Port has been a subject of interest in many research studies $[19,28,29]$. We choose Imwon Port as our study area to perform damage assessment for buildings because of its unique location and vulnerability to tsunamis. A field survey was performed to gather building information about typography (building material, usage), which is shown in Figure 4.

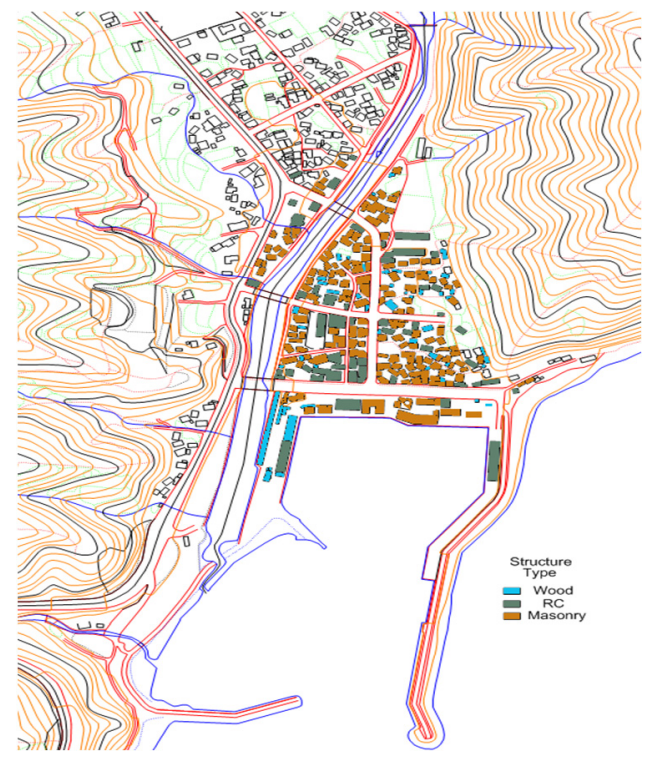

Figure 4. Building structural types in areas vulnerable to tsunami inundation.

\subsection{Numerical Model}

Our model is a combination of long-distance tsunami propagation and run-up processes along shorelines. Linear Boussinesq equations are recommended for modeling tsunami propagation; 
however, these equations present a complication in numerical discretization [21]. Therefore, we use a system of linear shallow-water equations with modifications introduced to represent the frequency dispersion and Coriolis force observed in transoceanic tsunami propagation. The linear shallow-water equations are discretized by a leap-frog scheme based on the finite difference method, as proposed by Ha and Cho in [24].

$$
\frac{\zeta_{i, j}^{n+1 / 2}-\zeta_{i, j}^{n-1 / 2}}{\Delta t}+\frac{P_{i+1 / 2, j}^{n}-P_{i-1 / 2, j}^{n}}{\Delta x}+\frac{Q_{i, j+1 / 2}^{n}-Q_{i, j-1 / 2}^{n}}{\Delta y}=0
$$

$$
\begin{aligned}
& P_{i+1 / 2, j}^{n+1}-P_{i+1 / 2, j}^{n}+g h_{i+1 / 2, j} \frac{\zeta_{i+1, j}^{n+1 / 2}-\zeta_{i, j}^{n+1 / 2}}{\Delta t}+\frac{\alpha}{12 \Delta x} g h_{i+1 / 2, j}\left[\zeta_{i+2, j}^{n+1 / 2}-3 \zeta_{i+1, j}^{n+1 / 2}+3 \zeta_{i, j}^{n+1 / 2}-\zeta_{i-1, j}^{n+1 / 2}\right] \\
& +\frac{\gamma}{12 \Delta x} g h_{i+1 / 2, j}\left[\left(\zeta_{i+1, j+1}^{n+1 / 2}-2 \zeta_{i+1, j}^{n+1 / 2}+\zeta_{i+1, j-1}^{n+1 / 2}\right)^{n+1}-\left(\zeta_{i, j+1}^{n+1 / 2}-2 \zeta_{i, j}^{n+1 / 2}+\zeta_{i, j-1}^{n+1 / 2}\right)\right] \\
& -\frac{\beta}{12} g b\left(\zeta_{i, j+1}^{n+1 / 2}-2 \zeta_{i, j}^{n+1 / 2}+\zeta_{i, j-1}^{n+1 / 2}\right)-\frac{\delta}{12} g b\left(\zeta_{i+1, j}^{n+1 / 2}-2 \zeta_{i, j}^{n+1 / 2}+\zeta_{i-1, j}^{n+1 / 2}\right)=0 \\
& \frac{Q_{i, j+1 / 2}^{n+1}-Q_{i, j+1 / 2}^{n}}{\Delta t}+g h_{i, j+1 / 2} \frac{\zeta_{i, j+1}^{n+1 / 2}-\zeta_{i, j}^{n+1 / 2}}{\Delta y}+\frac{\alpha}{12 \Delta y} g h_{i, j+1 / 2}\left[\zeta_{i, j+2}^{n+1 / 2}-3 \zeta_{i, j+1}^{n+1 / 2}+3 \zeta_{i, j}^{n+1 / 2}-\zeta_{i, j-1}^{n+1 / 2}\right] \\
& +\frac{\gamma}{12 \Delta y} g h_{i, j+1 / 2}\left[\left(\zeta_{i+1, j+1}^{n+1 / 2}-2 \zeta_{i, j+1}^{n+1 / 2}+\zeta_{i-1, j+1}^{n+1 / 2}\right)-\left(\zeta_{i+1, j}^{n+1 / 2}-2 \zeta_{i, j}^{n+1 / 2}+\zeta_{i-1, j}^{n+1 / 2}\right)\right] \\
& -\frac{\beta}{12} g a\left(\zeta_{i+1, j}^{n+1 / 2}-2 \zeta_{i, j}^{n+1 / 2}+\zeta_{i-1, j}^{n+1 / 2}\right)-\frac{\delta}{12} g a\left(\zeta_{i, j+1}^{n+1 / 2}-2 \zeta_{i, j}^{n+1 / 2}+\zeta_{i, j-1}^{n+1 / 2}\right)=0
\end{aligned}
$$

where $\zeta(t, x, y)$ is free surface displacement, $h$ is still-water depth, $P$ and $Q$ are depth-averaged volume fluxes in $x$ and $y$ directions equal to $(H \bar{u})$ and $(H \bar{v})$, respectively, and $g$ is gravitational acceleration. $\beta$ and $\gamma$ are dispersion correction factors given as

$$
\beta=\frac{-20 h^{2}+g h \Delta t^{2}+\Delta x^{2}}{\Delta x^{2}}, \delta=\frac{\Delta x^{2}-24 h^{2}}{\Delta x^{2}}
$$

The coefficients $a$ and $b$ are approximated as:

$$
a=\frac{\partial h}{\partial x}, b=\frac{\partial h}{\partial y}
$$

Equations (2)-(4) are not valid in regions where the amplitude of the tsunami is larger than its wavelength; near coastal regions, friction has significant effects on flow, dispersion has minimal effects, and the flow behaves like shallow-water flow. The non-linear shallow-water equations are used to model this flow motion:

$$
\begin{gathered}
\frac{\partial \zeta}{\partial t}+\frac{\partial(H \bar{u})}{\partial x}+\frac{\partial(H \bar{v})}{\partial x}=0 \\
\frac{\partial(H \bar{u})}{\partial t}+\frac{\partial\left(H \bar{u}^{2}\right)}{\partial x}+\frac{\partial(H \overline{u v})}{\partial y}=-g h \frac{\partial \zeta}{\partial x}-\tau_{x} H \\
\frac{\partial(H \bar{v})}{\partial t}+\frac{\partial(H \overline{u v})}{\partial x}+\frac{\partial\left(H \bar{v}^{2}\right)}{\partial y}=-g H \frac{\partial \zeta}{\partial y}-\tau_{y} H
\end{gathered}
$$

where $H=\zeta+h$ is the total depth of the water column, and $\bar{u}, \bar{v}$ are depth-averaged velocities in $x$ and $y$ directions, respectively. The friction terms $\tau_{x}$ and $\tau_{y}$ are estimated by Manning's formula

$$
\tau_{x}=\frac{g n^{2}}{H^{10 / 3}} P\left(P^{2}+Q^{2}\right)^{1 / 2}, \tau_{y}=\frac{g n^{2}}{H^{10 / 3}} Q\left(P^{2}+Q^{2}\right)^{1 / 2}
$$

where Manning's roughness coefficient $n$ is equal to 0.025 . The linear terms of Equations (7)-(9) are also discretized by a leap-frog scheme; for non-linear terms in Equations (8) and (9), we used the upwind method proposed in [30].

The computational domain is discretized into a staggered mesh system, which is divided into six regions $(\mathrm{A}-\mathrm{F})$ with successive refined grids. The use of six nested regions improves the resolution of the 
study area. To make computations economical for the vast domain, the mesh system is also temporally staggered. The computational domain is shown in Figure 5, and the mesh details are given in Table 3. The topographic and bathymetric data used in numerical modeling were purchased from the "National Geographic Information Institute (NGII)" and "Korea Hydrographic and Oceanographic Agency (KHOA)", respectively. The proposed numerical scheme also considers the effects of existing seawalls and breakwaters on the tsunami features for accurate predictions. Moving boundary conditions are used to advance the solution for which details can be found in [31].

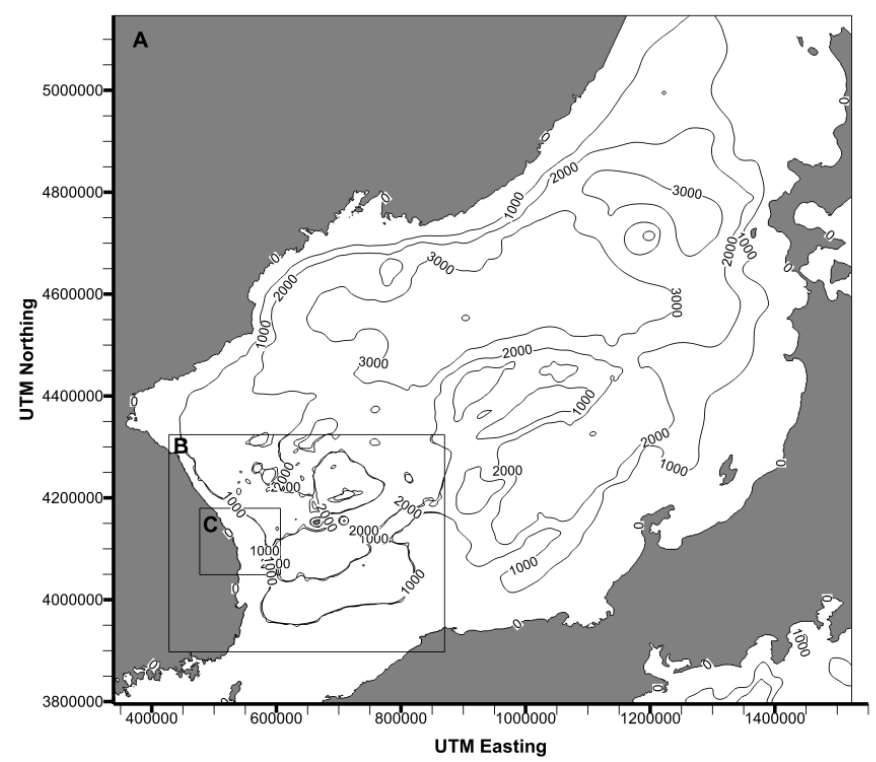

(a)

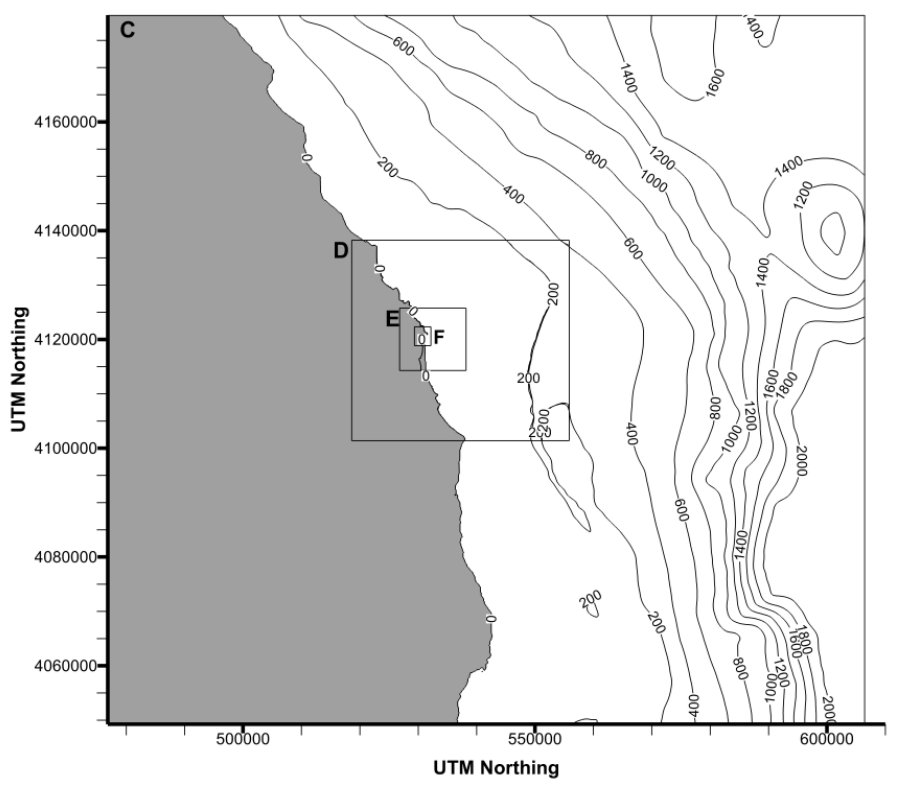

(b)

Figure 5. Nestled grid for Imwon Port, (a) regions A-C; (b) regions C-F. 
Table 3. Computational mesh details.

\begin{tabular}{cccccc}
\hline \multirow{2}{*}{ Region } & \multirow{2}{*}{ Grid Size (m) } & \multicolumn{2}{c}{ Mesh Number } & Time Step Size (s) & \multirow{2}{*}{ Type of Numerical Model } \\
& & $x$ & $y$ & 3.0 & LSWE \\
A & 1215 & 976 & 1114 & 1.0 & LSWE \\
B & 405 & 1093 & 1054 & 0.33 & LSWE \\
C & 135 & 961 & 967 & 0.11 & LSWE \\
D & 45 & 829 & 820 & 0.04 & NLSWE \\
E & 15 & 760 & 766 & 0.04 & NLSWE \\
F & 4.5 & 568 & 694 & & \\
\hline
\end{tabular}

Historical records show that the damage caused at Imwon Port is predominantly due to flooding. Because of its distance from the source of the tsunami generation, much of the energy of tsunami wave is dispersed. Therefore, we only consider the maximum flood depth as a demand parameter, obtained by simulating the tsunami propagation for 11 hypothetical cases and three historical cases. The simulation results provide a complete time history of flow depths over the inundated area. After the occurrence of a submarine earthquake, the first tsunami wave strikes Imwon Port after $120 \mathrm{~min}$, for roughly all the hypothetical cases studied in this paper. Depending upon the fault parameters, the maximum inundation depth and area varies. We performed simulations for a total of $150 \mathrm{~min}$, and the results for each case are shown in Figure 6.

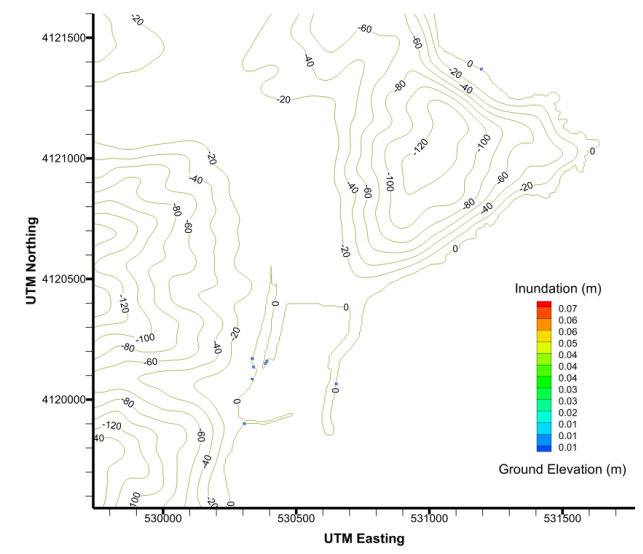

(a)

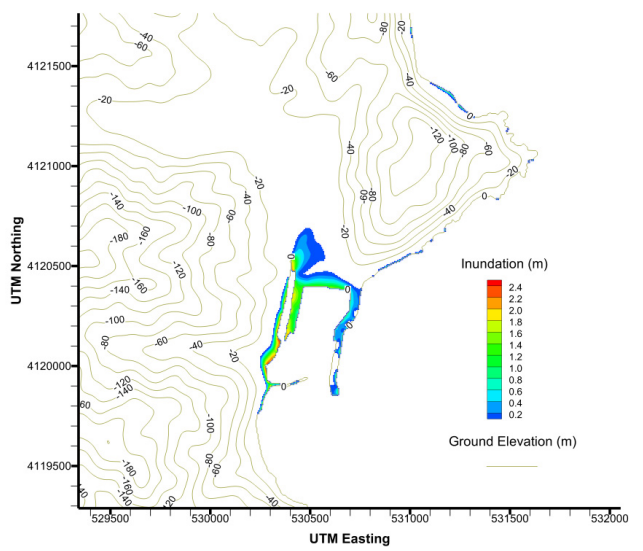

(c)

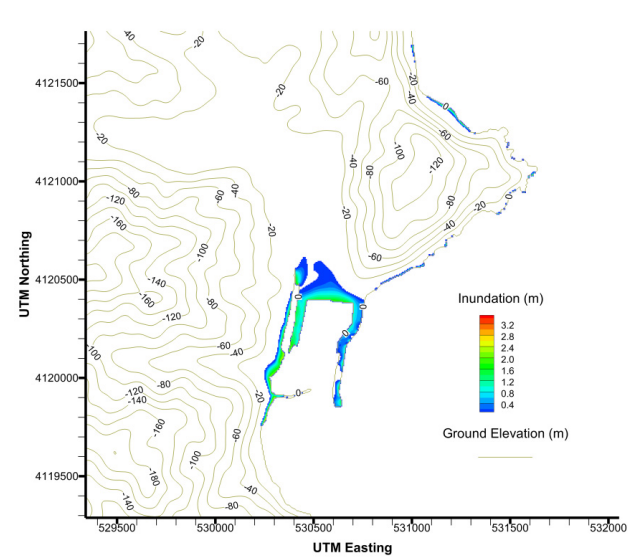

(b)

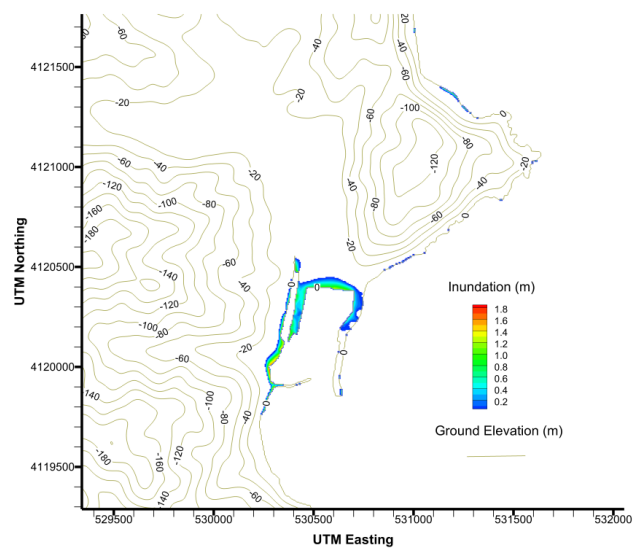

(d)

Figure 6. Cont. 


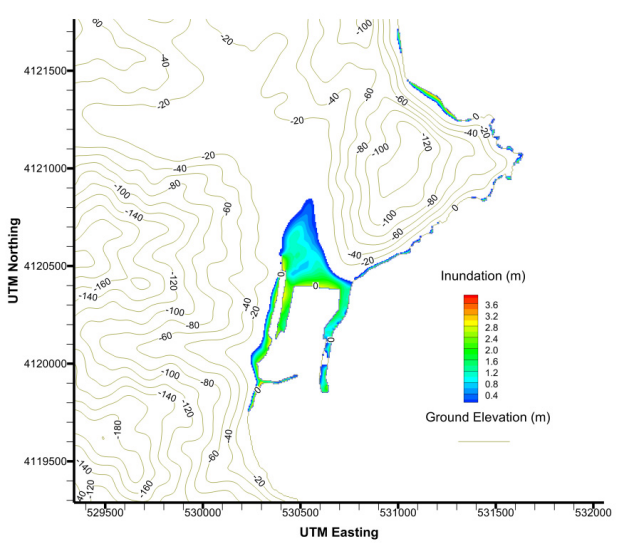

(e)

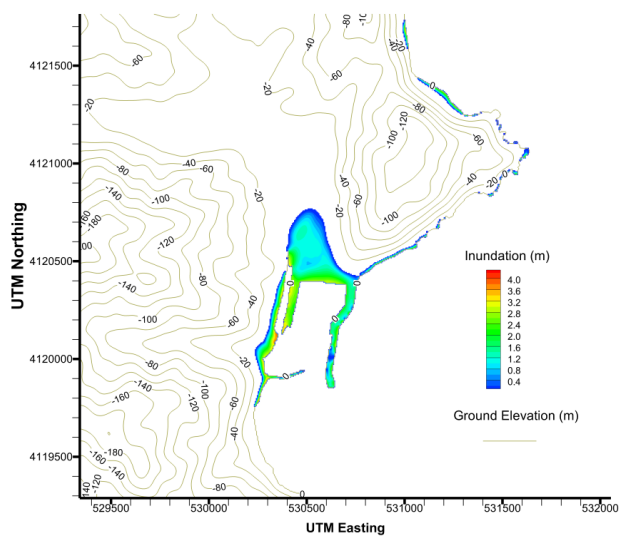

(g)

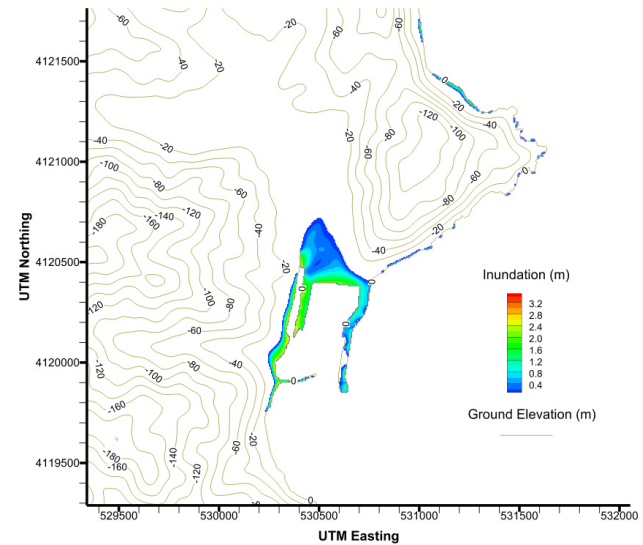

(i)

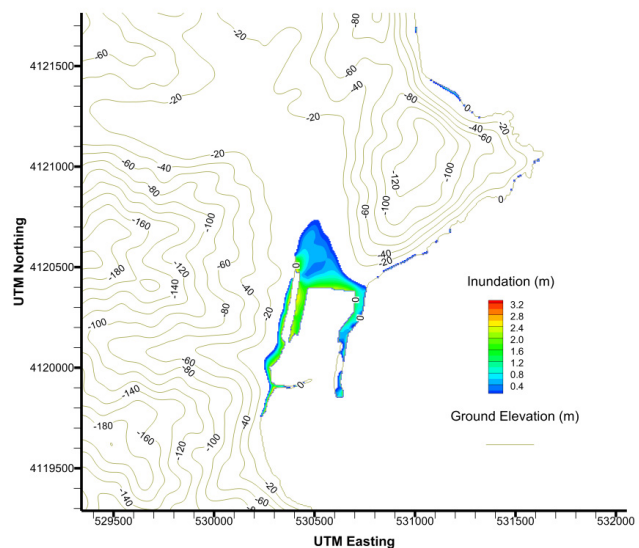

(k)

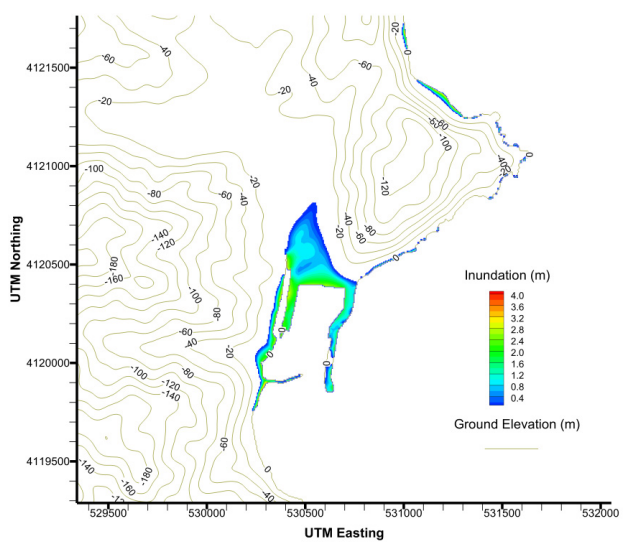

(f)

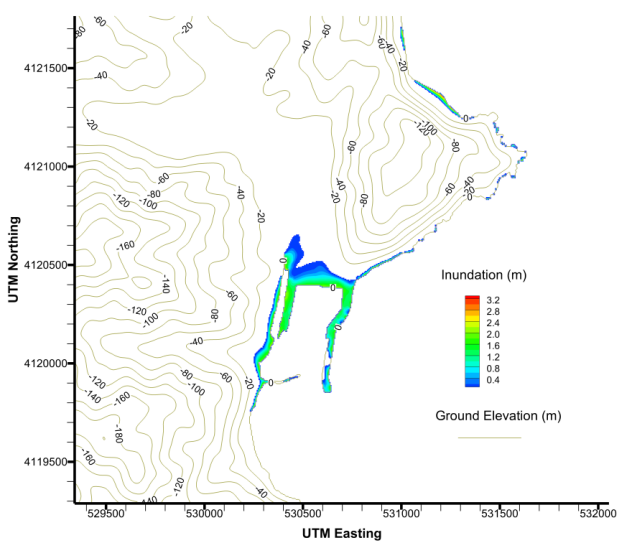

(h)

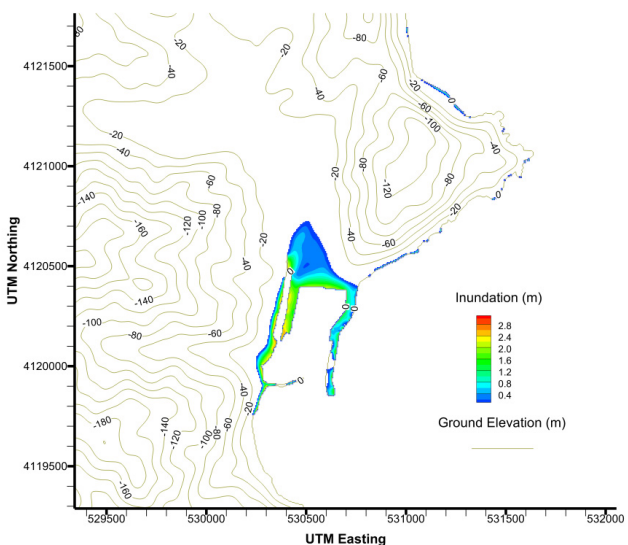

(j)

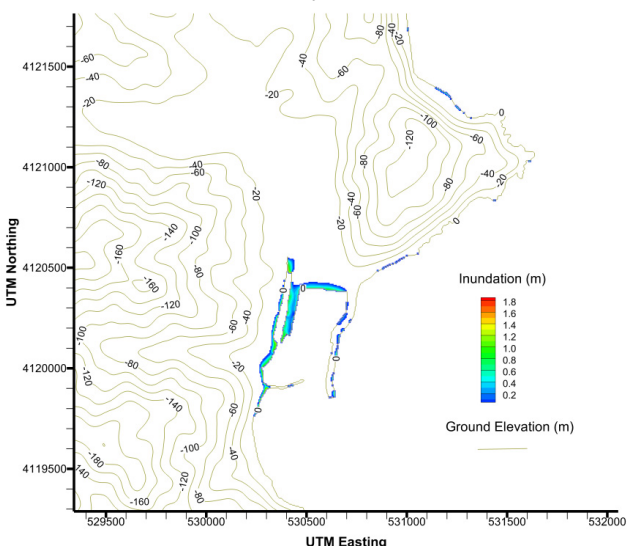

(1)

Figure 6. Cont. 


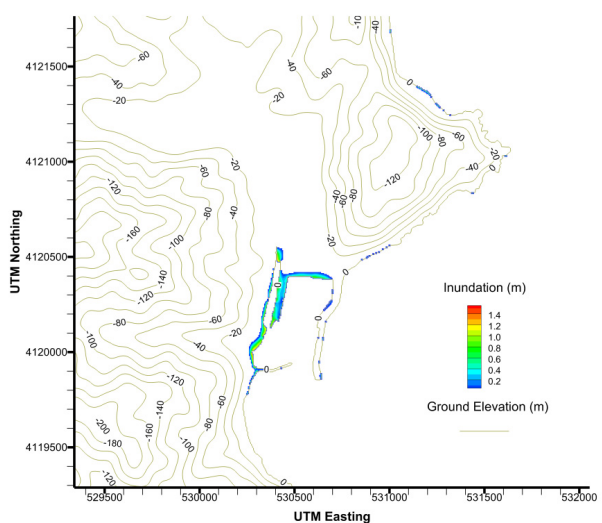

$(\mathbf{m})$

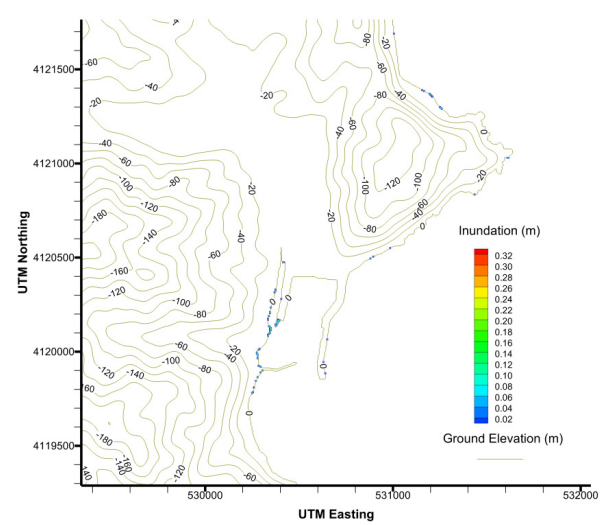

(n)

Figure 6. Numerical model results for cases 1-11 and three historical tsunamis. (a) 1964; (b) 1983; (c) 1993; (d) Case 1; (e) Case 2; (f) Case 3; (g) Case 4; (h) Case 5; (i) Case 6; (j) Case 7; (k) Case 8; (l) Case 9; (m) Case 10; (n) Case 11.

Since we are interested in estimating the damage probability for structures, the maximum depth observed at each grid point, among all the historical and hypothetical tsunami cases is extracted in Figure 7. This procedure provides the maximum inundation at each grid point. The topographic contours are negative in our numerical model, as shown in Figures 6 and 7.

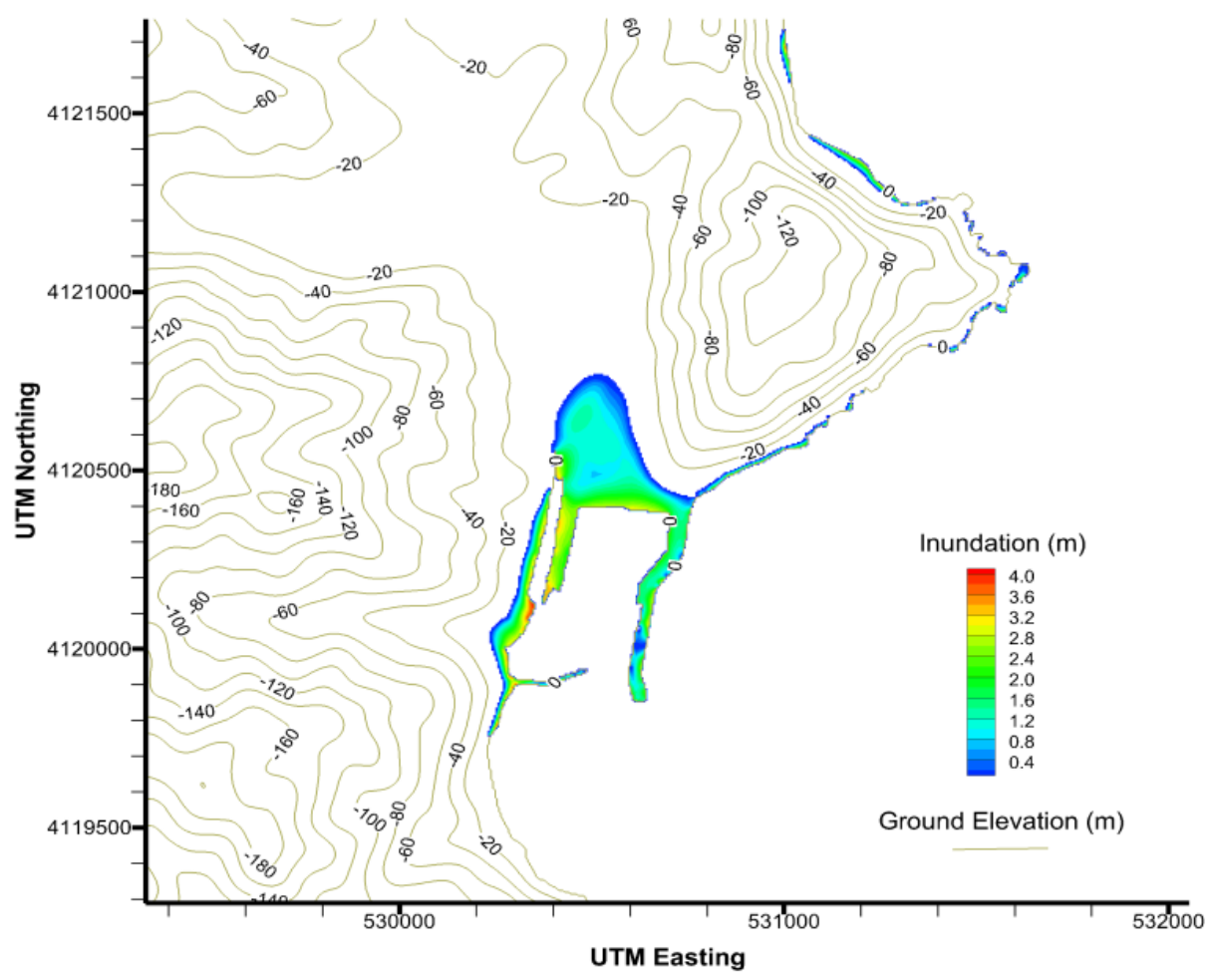

Figure 7. Maximum inundation map.

The maximum inundation depths obtained from the numerical model (Figure 7) are then plotted on the geographical map shown in Figure 8 in order to assess the extent of the flooded area and flood depths at the individual building level. 


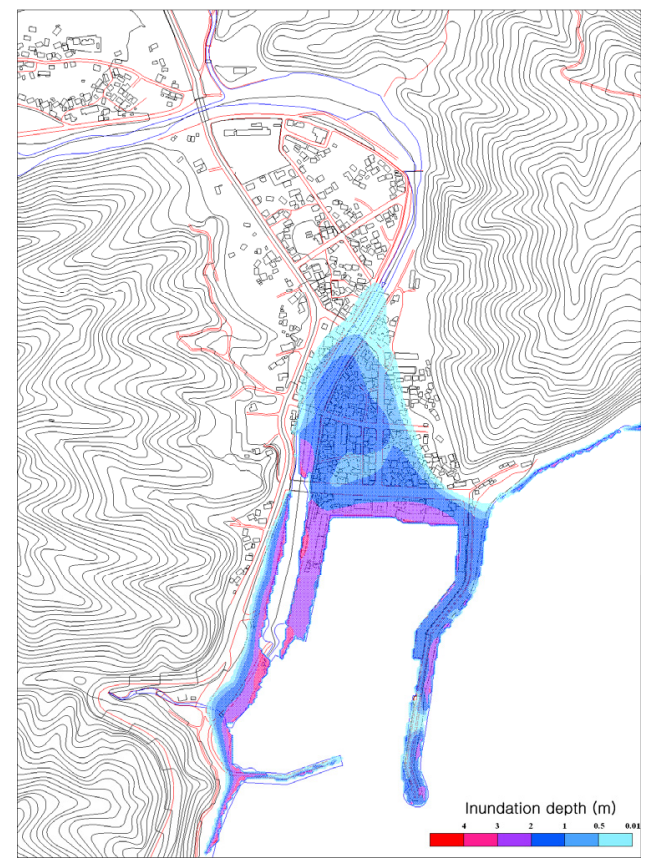

Figure 8. Maximum inundation depths and area derived from 14 numerically modeled cases in Imwon Port.

\section{Results and Discussion}

The building damage data for Imwon Port are scarce; the area was severely affected by the 1983 tsunami and 44 buildings were destroyed, damaged, or flooded [32]. Since data on the number and typography of the damaged structures at Imwon Port during the 1983 and 1993 tsunamis are not available, our structure damage estimates are based on fragility curves developed in a previous study [9].

The damage probabilities of structures vulnerable to tsunamis are expressed as fragility functions. A number of hydrodynamic features can be considered demand parameters in fragility functions. Most of the existing works $[4,7,15,25,33]$ derive fragility curves based on inundation depths as the only demand parameter. However, $[9,17]$ recommended that other tsunami features like velocity, force, scouring, and debris impact to be included in the model. The analysis of historical tsunami flow records for Imwon Port shows that flow velocity does not pose a serious risk to structures in the study area, and damage was mostly caused by flooding. This is because the east coast of Korea is very far from the historical and hypothetical tsunami origins on the west coast of Japan. When the waves reach the east coast, much of the energy is dissipated, resulting in lower wave velocity and consequently, lower hydrodynamic forces, which are not capable of causing serious damage to structures located in that region. Therefore, we only consider structure damage probabilities based on inundation depths.

The choice of a particular set of fragility curves for damage estimates is based on the similarity of construction practices, tsunami hydrodynamic features, damage classification, and building typography. There are a number of empirically developed fragility curves available in the literature. [33,34] developed fragility curves for areas affected by the 2004 Indian Ocean tsunami in Sri Lanka, and [35] estimated fragility curves for Banda Aceh and South Java in Indonesia. Most of the existing work on fragility curves was performed in Japan after the 2011 tsunami $[4,9,18,25]$. Based on a comparison of construction practices and building typologies, we choose the fragility curves presented in [9] to estimate structure damage in Imwon Port. These curves are based on fragility functions developed for Kesennuma (Japan), which was extensively damaged by the 2011 tsunami. The use of ordinal regression analysis in [9] addresses the issues of damage uncertainty associated with 
linear regression and the shortcoming of logistic regression in that it does not utilize all the damage information [18].

The fragility curves in [9], shown in Figure 9, are based on damage information of 19,815 buildings. The construction material of the surveyed buildings was reinforced concrete (RC), steel, wood, and masonry. In our study, we performed damage estimates for the three construction materials, RC, masonry, and wood, since the maximum inundated area shown in Figure 8 does not include any steel structure at risk of being damaged. The damage states we used are adopted from [9]. Based on the study of inundation depths provided by our numerical model, we modified the damage scale provided by Japan's Ministry of Land, Infrastructure, Transport, and Tourism (MLIT) into four states, from minor to complete damage, as shown in Table 4.

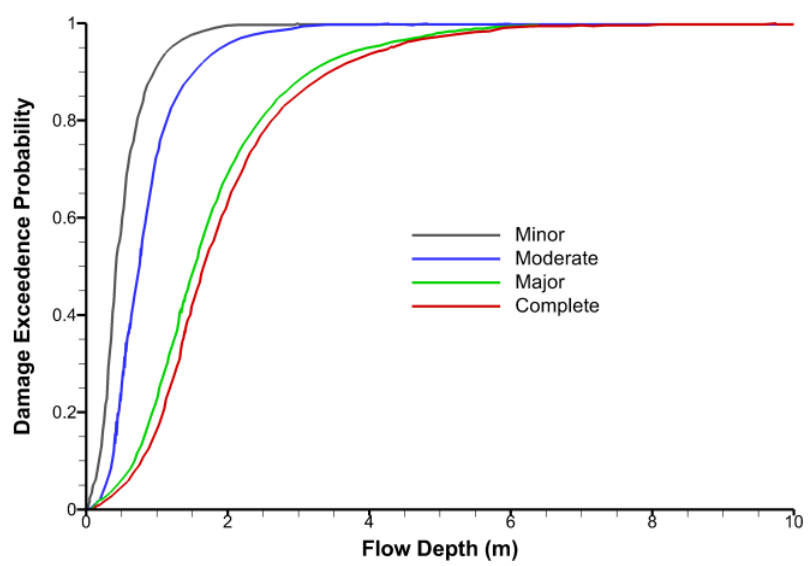

(a)

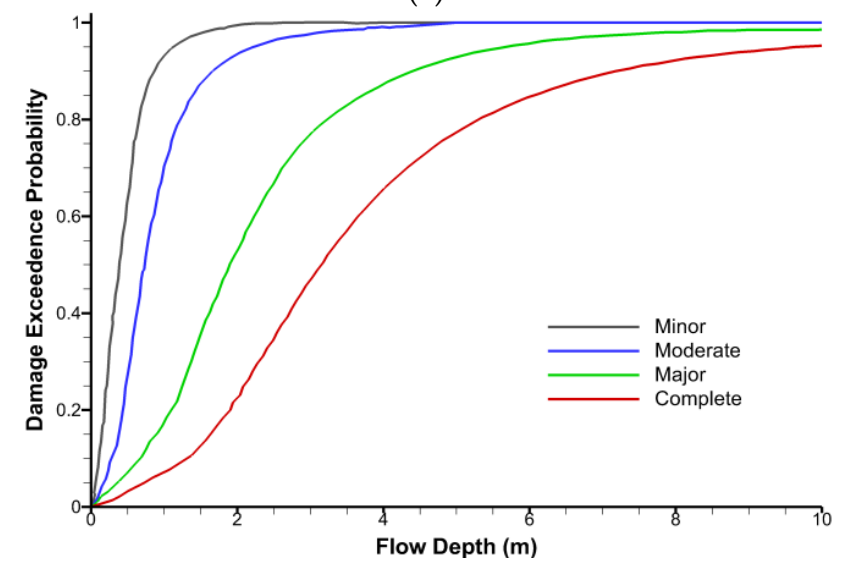

(b)

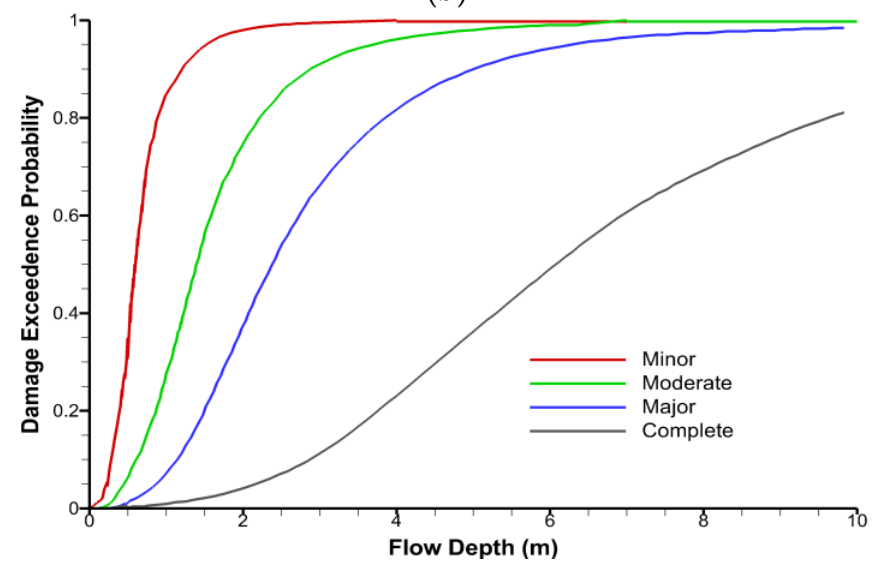

(c)

Figure 9. Fragility curves for (a) wood; (b) masonry; and (c) RC, as proposed in [9]. 
Table 4. Tsunami damage scale devised by the Ministry of Land, Infrastructure, Transport and Tourism (MLIT) in Japan.

\begin{tabular}{cccc}
\hline Designation & Damage Classification & Damage Description & Structure Condition \\
\hline DL1 & Minor & Flood only & Reusable after floor cleaning \\
\hline DL2 & Moderate & No structural damage & Reusable after minor repairs \\
\hline DL3 & Major & $\begin{array}{c}\text { Partially damaged walls but } \\
\text { no damage to columns }\end{array}$ & $\begin{array}{c}\text { Might be reusable } \\
\text { after major repair }\end{array}$ \\
\hline DL4 & Complete & $\begin{array}{c}\text { Extensive damage to walls, } \\
\text { some damage to columns }\end{array}$ & $\begin{array}{c}\text { Might be reusable after } \\
\text { major repair in some cases }\end{array}$ \\
\hline
\end{tabular}

Based on the maximum inundation depths presented in Figures 7 and 8 the flooding depths assigned to each building in the inundated area are shown in Figure 10; the purpose is to estimate the damage probability for each structure using fragility analysis of the curves presented for each structure type in Figure 9. The number of buildings at risk for flood in the study area are 185, 113 of which are masonry, 41 are RC, and 31 are wooden or made of prefabricated material.

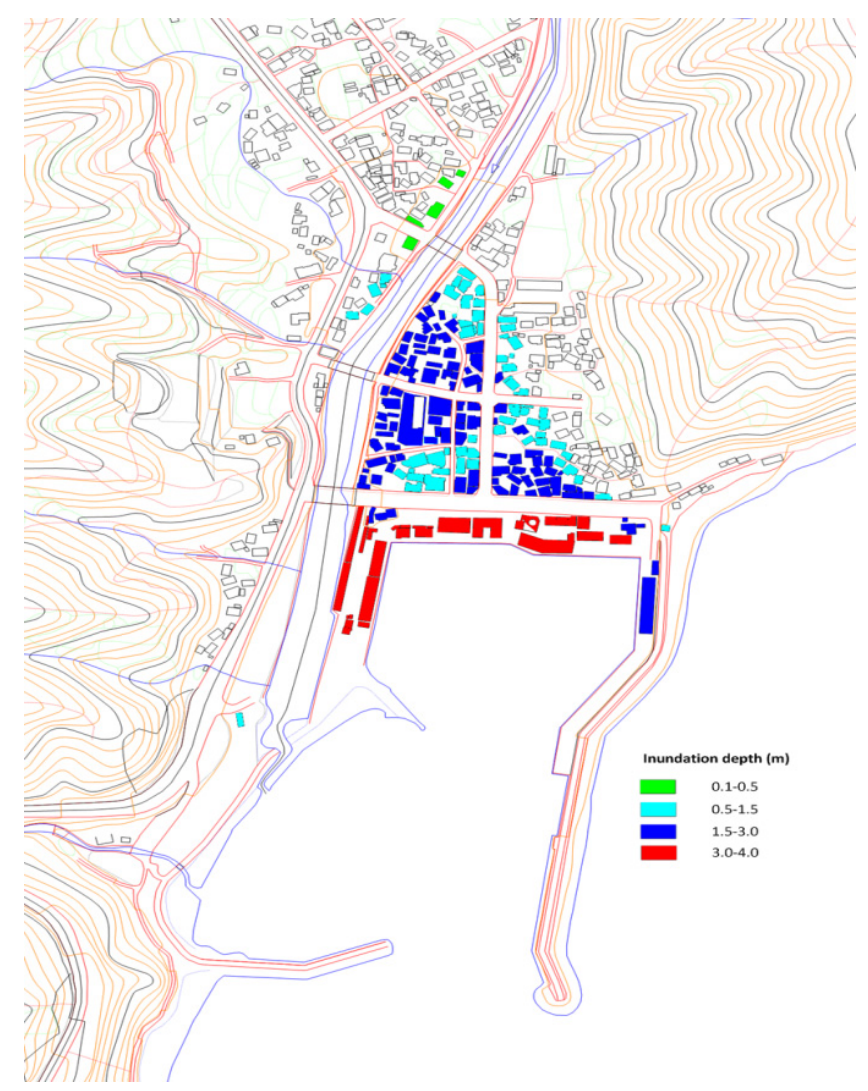

Figure 10. Inundation depths for structures in the flooded area.

After analyzing inundation depths for each structure with fragility curves, we calculate the probabilities of minor, moderate, major, and complete damage for all inundated buildings. As an example, we show in Figure 11 the probability of structures suffering major damage from a tsunami. The probability of major damage for most of the buildings is less than $25 \%$. As expected, the RC buildings show the least probability of major damage. For inundation depths between 0.01 and $2 \mathrm{~m}$, the majority of the structures have a major damage probability $<25 \%$. The largest variation in damage probability occurs for depths between 2 to $3.5 \mathrm{~m}$. Structures close to the shoreline have the highest probability of damage, with wooden structures expected to be completely destroyed. We observe 
that the damage probabilities are low over the entire area except for minor and moderate damage. Table 5 summarizes the total number of buildings in each damage class for each type of material; the calculations are based on maximum inundation depth and area.

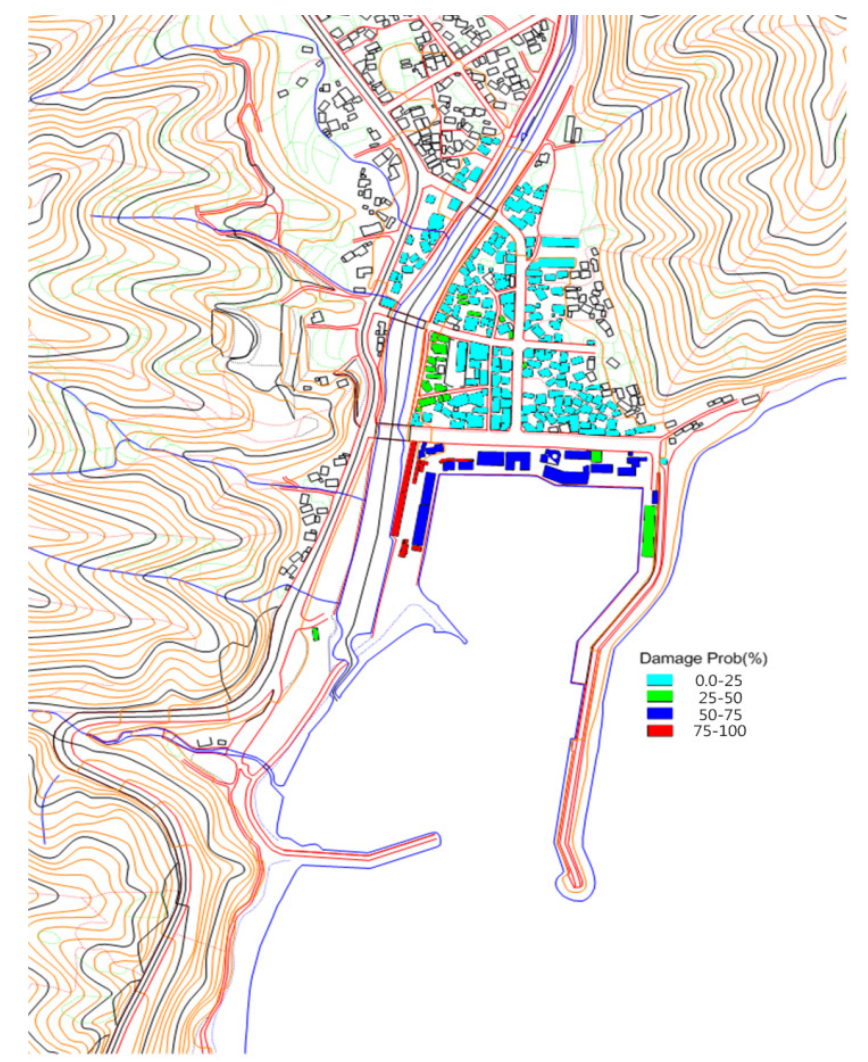

Figure 11. Percentage probability for structures undergoing major damage due to tsunami.

Table 5. Number of buildings at each damage level according to the structure material type.

\begin{tabular}{cccccccccccccc}
\hline Str. Type & \multicolumn{1}{c}{ Wood } & \multicolumn{1}{c}{ RC } & \multicolumn{1}{c}{ Masonry } \\
\hline \multicolumn{10}{c}{} & \multicolumn{1}{c}{ Damage Probability } \\
\hline Damage Level & $<25 \%$ & $>25 \%$ & $>50 \%$ & $>75 \%$ & $<25 \%$ & $>25 \%$ & $>50 \%$ & $>75 \%$ & $<25 \%$ & $>25 \%$ & $>50 \%$ & $>75 \%$ \\
Minor & 4 & 1 & 3 & 23 & 8 & 2 & 1 & 30 & 18 & 9 & 14 & 71 \\
Moderate & 5 & 4 & 5 & 17 & 11 & 0 & 19 & 5 & 28 & 11 & 28 & 37 \\
Major & 12 & 9 & 3 & 5 & 29 & 3 & 2 & 0 & 69 & 8 & 14 & 0 \\
Complete & 13 & 5 & 3 & 5 & 34 & 0 & 0 & 0 & 58 & 13 & 0 & 0 \\
\hline
\end{tabular}

The number of buildings and their probability of suffering minor damage vary for different typologies. Table 5 shows that a total of 31 wooden, $41 \mathrm{RC}$, and 112 masonry buildings suffer minor damage. The maximum flow depth observed was around $4.0 \mathrm{~m}$. A building damage threshold of $2 \mathrm{~m}$ for all building materials specified in [25] is validated in our study; regardless of the building material, all buildings with an inundation depth $\geqslant 2 \mathrm{~m}$ may suffer significant moderate or major damage, while wooden structures may suffer complete damage. Table 5 shows that RC buildings are most resilient to all damage classes, followed by masonry and wooden structures. Since most of the wooden structures are not in the high flood zone, there are only 5 buildings with major and complete damage probabilities greater than $75 \%$. It is observed that regardless of the construction material, almost all structures are expected to experience minor damage, with probability of damage being the lowest for RC buildings. 


\section{Conclusions}

The fragility analysis of buildings shows the damage probability for hazards, which can be used to identify areas (buildings) most vulnerable to flood damage and consequently, can be vital for improving existing infrastructure and planning future development for safeguarding purposes. To prevent or minimize large-scale destruction it is important to perform damage assessment of vulnerable structures. By analyzing inundation depths, flow velocity and discharge from numerical modeling of tsunamis, fragility curves can be obtained for the areas susceptible to flooding. This approach can serve as an indirect measure of structural vulnerability; however, for areas with little or no record of damage caused by tsunami, accurate fragility curves cannot be developed. The concept of using existing fragility curves to determine structural damage probability is new, with major contributions from $[7,12,13]$. We extend this idea to Imwon Port in Korea by proposing improved numerical models with improved bathymetric resolution to capture flow features at the individual structure level; we also use fragility curves based on an advanced statistical approach and vast building damage data from the 2011 Great East Tsunami in Japan.

We produce probability damage maps for four damage levels and three structure types. Clear patterns of damage trends and behaviors of each structure type in response to tsunami flow features cannot be observed unless there is a large number of structures in the inundated area. We found little variation in damage probabilities at low inundation depths with all structures, regardless of the construction material. The damage probability for wooden structures is the most sensitive to variation in flood depth, followed by masonry structures, while RC buildings are the most resilient to damage, particularly to major and complete damage. The proposed technique may provide decision makers with a better understanding of risk assessment for mitigating the effects of potential disasters in areas with little or no record of structural damage from previous tsunamis.

Acknowledgments: This research was a part of the project titled "Study on Solitary Wave Run-up for Hazard Mitigation of Coastal Communities against Sea Level Rise", funded by the Ministry of Oceans and Fisheries, Korea.

Author Contributions: Khawar Rehman and Yong-Sik Cho conceived and designed the numerical simulations; Khawar Rehman performed the simulations, analyzed the data, and wrote the paper; Yong-sik Cho contributed providing data/materials/analysis tools.

Conflicts of Interest: The authors declare no conflict of interest.

\section{References}

1. Tarbotton, C.; Dall'Osso, F.; Dominey-Howes, D.; Goff, J. The use of empirical vulnerability functions to assess the response of buildings to tsunami impact: Comparative review and summary of best practice. Earth-Sci. Rev. 2015, 142, 120-134. [CrossRef]

2. Cho, Y.-S.; Kim, Y.C.; Kim, D. On the spatial pattern of the distribution of the tsunami run-up heights. Stoch. Environ. Res. Risk Assess. 2013, 27, 1333-1346. [CrossRef]

3. Suppasri, A.; Kamthonkiat, D.; Gokon, H.; Matsuoka, M.; Koshimura, S. Application of Remote Sensing for Tsunami Disaster; INTECH Open Access Publisher: Shanghai, China; Rijeka, Croatia, 2012; pp. 143-168.

4. Suppasri, A.; Mas, E.; Charvet, I.; Gunasekera, R.; Imai, K.; Fukutani, Y.; Abe, Y.; Imamura, F. Building damage characteristics based on surveyed data and fragility curves of the 2011 Great East Japan tsunami. Nat. Hazards 2013, 66, 319-341. [CrossRef]

5. Shinozuka, M.; Feng, M.Q.; Lee, J.; Naganuma, T. Statistical analysis of fragility curves. J. Eng. Mech. 2000, 126, 1224-1231. [CrossRef]

6. Koshimura, S.; Namegaya, Y.; Yanagisawa, H. Tsunami fragility-A new measure to identify tsunami damage. J. Disaster Res. 2009, 4, 479-488.

7. Valencia, N.; Gardi, A.; Gauraz, A.; Leone, F.; Guillande, R. New tsunami damage functions developed in the framework of SCHEMA project: Application to European-Mediterranean coasts. Nat. Hazards Earth Syst. Sci. 2011, 11, 2835-2846. [CrossRef] 
8. Akiyama, M.; Frangopol, D.M.; Arai, M.; Koshimura, S. Probabilistic assessment of structural performance of bridges under tsunami hazard. In Proceedings of the Structures Congress 2012, Chicago, IL, USA, 29-31 March 2012; ASCE: Reston, VA, USA, 2012.

9. Charvet, I.; Suppasri, A.; Kimura, H.; Sugawara, D.; Imamura, F. A multivariate generalized linear tsunami fragility model for Kesennuma City based on maximum flow depths, velocities and debris impact, with evaluation of predictive accuracy. Nat. Hazards 2015, 79, 2073-2099. [CrossRef]

10. Hayashi, S.; Koshimura, S. The 2011 Tohoku tsunami flow velocity estimation by the aerial video analysis and numerical modeling. J. Disaster Res. 2013, 8, 561-572.

11. Koshimura, S.; Oie, T.; Yanagisawa, H.; Imamura, F. Developing fragility functions for tsunami damage estimation using numerical model and post-tsunami data from Banda Aceh, Indonesia. Coast. Eng. J. 2009, 51, 243-273. [CrossRef]

12. Wiebe, D.M.; Cox, D.T. Application of fragility curves to estimate building damage and economic loss at a community scale: A case study of Seaside, Oregon. Nat. Hazards 2014, 71, 2043-2061. [CrossRef]

13. Park, H.; Wiebe, D.M.; Cox, D.T.; Cox, K. Tsunami inundation modeling: Sensitivity of velocity and momentumm flux to bottom friction with application to building damage at Seaside, Oregon. Coast. Eng. Proc. 2014, 1. [CrossRef]

14. Di Mauro, M.; de Bruijn, K.M.; Meloni, M. Quantitative methods for estimating flood fatalities: Towards the introduction of loss-of-life estimation in the assessment of flood risk. Nat. Hazards 2012, 63, 1083-1113. [CrossRef]

15. Reese, S.; Bradley, B.A.; Bind, J.; Smart, G.; Power, W.; Sturman, J. Empirical building fragilities from observed damage in the 2009 South Pacific tsunami. Earth-Sci. Rev. 2011, 107, 156-173. [CrossRef]

16. Cimellaro, G.P.; Reinhorn, A. Multidimensional performance limit state for hazard fragility functions. J. Eng. Mech. 2010, 137, 47-60. [CrossRef]

17. Mas, E.; Koshimura, S.; Suppasri, A.; Matsuoka, M.; Matsuyama, M.; Yoshii, T.; Jimenez, C.; Yamazaki, F.; Imamura, F. Developing Tsunami fragility curves using remote sensing and survey data of the 2010 Chilean Tsunami in Dichato. Nat. Hazards Earth Syst. Sci. 2012, 12, 2689-2697. [CrossRef]

18. Charvet, I.; Ioannou, I.; Rossetto, T.; Suppasri, A.; Imamura, F. Empirical fragility assessment of buildings affected by the 2011 Great East Japan tsunami using improved statistical models. Nat. Hazards 2014, 73, 951-973. [CrossRef]

19. Cho, Y.-S. Numerical simulations of tsunamis in the East Sea, Korea. Disaster Adv. 2014, 7, 18-25.

20. Ha, T.-M.; Cho, Y.-S.; Choi, M.-K.; Jeong, W.-C. Run-up heights of Tsunami along the Eastern Coast of the Korean Peninsula. J. Coast. Res. SI 2007, 50, 348-352.

21. Cho, Y.-S.; Jin, S.-B.; Lee, H.-J. Safety analysis of Ulchin nuclear power plant against Nihonkai-Chubu earthquake tsunami. Nucl. Eng. Des. 2004, 228, 393-400. [CrossRef]

22. Lee, H.; Kim, K. Numerical simulation of tsunami inundation at the Imwon Port. In Proceedings of the Korea-China Conference on Port and Coastal Engineering, Seoul, Korea, 21-23 September 2000; p. 2123.

23. Choi, B.H.; Hong, S.J.; Pelinovsky, E. Simulation of prognostic tsunamis on the Korean coast. Geophys. Res. Lett. 2001, 28, 2013-2016. [CrossRef]

24. Ha, T.; Cho, Y.-S. Tsunami propagation over varying water depths. Ocean Eng. 2015, 101, 67-77. [CrossRef]

25. Suppasri, A.; Mas, E.; Koshimura, S.; Imai, K.; Harada, K.; Imamura, F. Developing tsunami fragility curves from the surveyed data of the 2011 Great East Japan tsunami in Sendai and Ishinomaki plains. Coast. Eng. J. 2012, 54, 1250008. [CrossRef]

26. Korean Peninsula Energy Development Organization. Estimation of Tsunami Height For KEDO LWR Project; Korea Power Engineering Company, Inc.: Yongin Si, Korea, 1999.

27. Mansinha, L.; Smylie, D. The displacement fields of inclined faults. Bull. Seismol. Soc. Am. 1971, 61, 1433-1440.

28. Park, D.; Cho, Y.-S.; Kim, S.-M. Simulation of Inundation at Imwon port during 1983 Central East Sea Tsunami. J. Coast. Res. 2007, 50, 1168-1172.

29. Choi, B.H.; Pelinovsky, E.; Kim, D.C.; Kim, K.O.; Kim, K.H. Three-dimensional simulation of the 1983 central East (Japan) Sea earthquake tsunami at the Imwon Port (Korea). Ocean Eng. 2008, 35, 1545-1559. [CrossRef]

30. Liu, P.L.-F.; Cho, Y.-S.; Briggs, M.J.; Kanoglu, U.; Synolakis, C.E. Runup of solitary waves on a circular island. J. Fluid Mech. 1995, 302, 259-285. [CrossRef] 
31. Cho, Y.S.; Liu, P.L.F. Crest-length effects in nearshore tsunami run-up around islands. J. Geophys. Res. 1999, 104, 7907-7913. [CrossRef]

32. Kim, H.-S. Occurrence of Tsunami and Warning System. Korean Soc. Mar. Eng. 2008, 32, 490-497. (In Korean) [CrossRef]

33. Peiris, N. Vulnerability functions for tsunami loss estimation. In Proceedings of the First European Conference on Earthquake Engineering and Seismology, a Joint Event of the 13th ECEE \& 30th General Assembly of the ESC, Geneva, Switzerland, 3-8 September 2006.

34. Dias, W.; Yapa, H.; Peiris, L. Tsunami vulnerability functions from field surveys and Monte Carlo simulation. Civ. Eng. Environ. Syst. 2009, 26, 181-194. [CrossRef]

35. Reese, S.; Cousins, W.; Power, W.; Palmer, N.; Tejakusuma, I.; Nugrahadi, S. Tsunami vulnerability of buildings and people in South Java-field observations after the July 2006 Java tsunami. Nat. Hazards Earth Syst. Sci. 2007, 7, 573-589. [CrossRef]

(C) 2016 by the authors; licensee MDPI, Basel, Switzerland. This article is an open access article distributed under the terms and conditions of the Creative Commons by Attribution (CC-BY) license (http://creativecommons.org/licenses/by/4.0/). 